\title{
UNA HISTORIA DE CRONOPIOS Y DE FAMAS. Diálogo con Andrés Jaque y Francesc Muñoz
}

\author{
Carolina Mateo Cecilia
}

A history of cronopios and famas. Dialogue with Andrés Jaque and Francesc Muñoz

Boletín Académico. Revista de investigación y arquitectura contemporánea

Escuela Técnica Superior de Arquitectura. Universidade da Coruña

elSSN 2173-6723

www.boletinacademico.com

Número 2 (2012)

Páginas 71-78

Fecha de recepción 25.10.2011

Fecha de aceptación 31.01.2012

https://doi.org/10.17979/bac.2012.2.0.979

\begin{abstract}
Resumen
Hoy en día, muchos de los esfuerzos del colectivo de arquitectos están centrados en materializar actuaciones de regeneración urbana. En este contexto, Francesc Muñoz y Andrés Jaque exponen que en la cotidianeidad del habitar existe una realidad que no se debe obviar. Esta realidad, difícil de cuantificar, emerge de aspectos como las prácticas ciudadanas, el contexto económico o las políticas internacionales; y determina el éxito o fracaso de una iniciativa urbana. El diálogo que aquí se presenta muestra, bajo diferentes lenguajes de expresión, que el rol adoptado por el arquitecto de hoy debe ser tan político como científico.
\end{abstract}

\begin{abstract}
Nowadays most of the architect's efforts are focused on making real urban refurbishment. In this context, Francesc Muñoz, and Andrés Jaque argue that in the daily fact of living there is a submerged reality that should not be skipped. This reality, difficult to quantify, emerges from aspects such as citizenship practices, the economic context or international policies, and determines the success or failure of an urban initiative. The dialogue here presented shows under different languages of expression, that the role adopted by the architect today must be such political as scientific.
\end{abstract}

\section{Palabras clave}

Arquitectura, ciudad, regeneración urbana, prácticas ciudadanas, rol del arquitecto.

\section{Keywords}

Architecture, city, urban refurbishment, citizenship practices, role of the architect. 


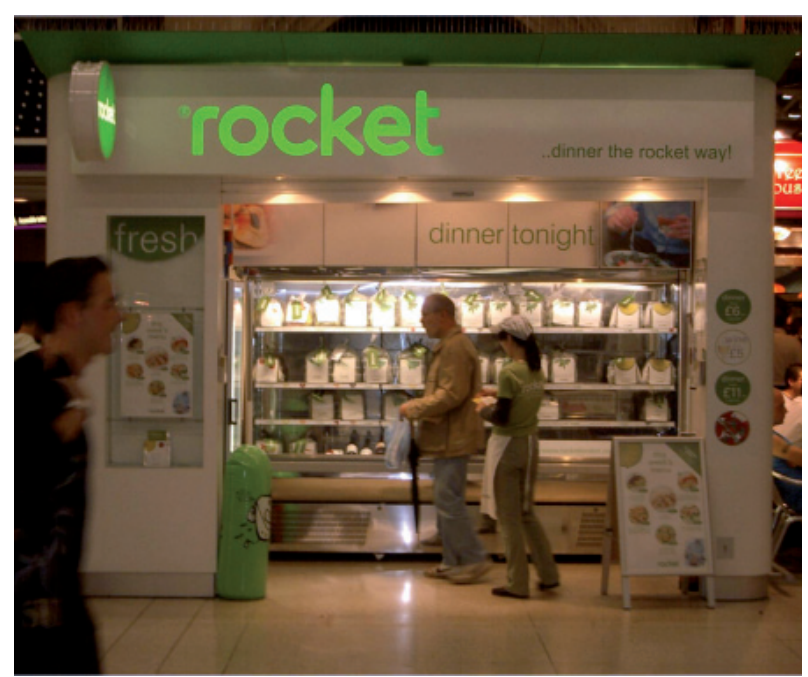

1 La imagen de un establecimiento Take Away en la London Victoria Station (2009) ayuda a visibilizar cómo los elementos que definen una realidad arquitectónica son heterogéneos, y provienen tanto del ámbito de lo técnico como de lo sociopolítico.

A finales de 2010, en la tercera edición del Foro para la Edificación Sostenible Comunitat Valenciana, pude coincidir con Andrés Jaque y Francesc Muñoz, dos urbanistas que partiendo de diferentes enfoques, llegan a resultados complementarios en sus investigaciones. De las reflexiones que se iniciaron en aquel Foro surge hoy este diálogo'1.

En clara alusión formal al famoso escrito de Max Webber El político y el cientifico ${ }^{2}$, planteamos que el técnico de hoy baraja simultáneamente elementos heterogéneos provenientes tanto del campo de la política como del científico-técnico, lejos de lo indicado por Weber (Fig. 01) ${ }^{3}$. Este debate abierto en relación al rol del arquitecto se inspira en los estudios sociales de la ciencia basados en la Teoría Actor Red ${ }^{4}$. Dichos estudios proponen herramientas pedagógicas y proyectuales tanto para arquitectos como para ingenieros, y buscan fomentar una visión intermedia entre las diferentes ramas del realismo y del constructivismo social, dotando a los técnicos de nuevas herramientas conceptuales para afrontar situaciones urbanas conflictivas'.

Por otro lado, existen iniciativas arquitectónicas que introducen prácticas etnográficas al proceso de diseño, volviendo a cuestionar una aproximación al ámbito urbano exclusivamente técnico, como por ejemplo el prototipo Casa rodante para una sociedad rodante, propuesto por Andrés Jaque (Fig. 02) ${ }^{6}$. Además, otras iniciativas minoritarias basadas en enfoques de género e intergeneracionales, o en herramientas de análisis provenientes de las teorías del desarrollo humano - como en el caso de la denominada teoría de las necesidades aplicada a la regeneración de barriosincluyen en mayor o menor medida dicha discusión sobre el rol del arquitecto 7 . A pesar de que no es objeto de esta entrevista ahondar en ninguna de ellas, se han querido introducir en el debate para entender el hilo argumental de las preguntas, con las limitaciones y riesgos que este hecho conlleva.

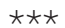

Francesc, Andrés, gracias por haber accedido a mantener esta conversación, y por haber mostrado interés por los debates promovidos desde el Foro ESCV. Recientemente, desde los ámbitos profesionales y académicos se presta más atención al hecho de que la profesión de los técnicos es tan politica (en el sentido amplio de la palabra) como cientifica. Este fenómeno, quizá más interiorizado por los profesionales que gestionan el territorio, está suponiendo un cambio de perspectiva en el modo de aproximarnos a la ciudad. Bajo este nuevo enfoque, ¿qué labor creéis que debe realizar hoy un técnico (arquitecto, ingeniero...)? ¿Se debería prestar más atención a aspectos como los procesos de apropiación de los espacios por los ciudadanos o la gestión de las intervenciones urbanas?

AJ: Es cierto que en estos momentos somos, por lo general, más conscientes de que los poseedores de conocimientos especializados y los especialistas son sólo una parte de los agentes que intervienen en los procesos de transformación social. Esta afirmación no conlleva un menoscabo de la autoridad del conocimiento especializado, sino que aumenta la certeza de que dicha autoridad del conocimiento debe asociarse día a día con otras formas no menos complejas. 


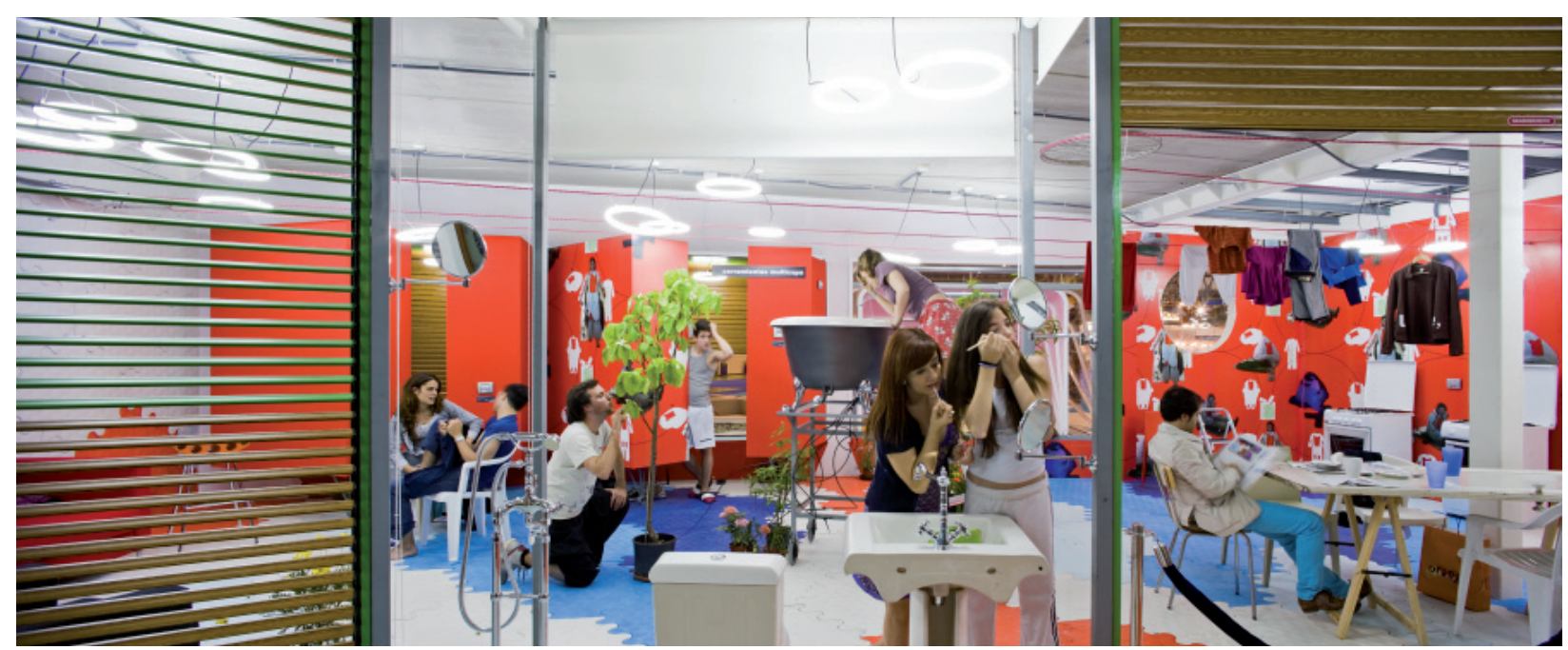

2 Andrés Jaque Arquitectos, Casa rodante para una sociedad rodante (2009); prototipo presentado en Barcelona. Esta casa fue diseñada apoyándose en los resultados de un estudio sobre hábitos de uso llevado a cabo por el autor.

Para mí, esto tiene varias implicaciones. La primera es que entre estos actores con afecciones diversas no es posible el consenso, por lo que se hace prioritario contar con marcos políticos que doten de garantías a los procesos de disputa. Lo segundo es que los procesos de transformación deben ser progresivos, y deben permitir en sus fases intermedias la evaluación de todos los agentes. Por estas razones hace años fundé la Oficina de Innovación Política, porque creo que es en este terreno en el que es necesario trabajar ahora desde la arquitectura y el urbanismo.

FM: El rol actual de los técnicos como arquitectos o ingenieros debe contextualizarse en un escenario urbano caracterizado por dos procesos complementarios: por un lado, la desinstitucionalización social de la figura del experto, y por otro, la multiplicación de los agentes sociales con visiones propias sobre la ciudad y el urbanismo. En cuanto a la primera cuestión, hoy en día los expertos deben argumentar y justificar mucho más sus decisiones, porque su autoridad técnica es más discutida. Sin duda, la pérdida de la confianza en el progreso técnico que ciento cincuenta años antes había encumbrado al experto, hoy juega en su contra.

En cuanto a la segunda cuestión, las sociedades urbanas actuales son mucho más complejas que las de momentos históricos anteriores, y se caracterizan por la existencia de grupos de población con visiones propias sobre la ciudad que reclaman tener voz sobre la evolución de la misma. En ese sentido, desde finales del siglo pasado se van sucediendo aportaciones que coinciden en reclamar más visibilidad para opinar y más capacidad para decidir sobre el diseño urbano y la planificación de la ciudad. Así, tanto la crítica de género como los trabajos que ponen de manifiesto las necesidades de colectivos y grupos de población como los nińos o los ancianos, han mostrado lo que no deja de ser una obviedad: que el papel que el experto tenía en la ciudad moderna como dador del saber técnico y tutor de la ciudad, es insostenible como tal en unos espacios urbanos donde cada vez más colectivos sociales reclaman su derecho a la ciudad.

En estos momentos en los que gran parte de los esfuerzos del colectivo están puestos en la regeneración urbana y la rehabilitación, ambos estaréis de acuerdo en afirmar que disponemos de poca información sobre las personas que habitan nuestras ciudades. El Censo de Población y Vivienda que se lleva a cabo cada diez años constituye la fuente más completa de información, pero su frecuencia es demasiado baja, y la mayoría de registros municipales resultan insuficientes y a menudo están descoordinados entre sí. Por otro lado, en algunos países europeos existen bases de datos georreferenciadas que identifican aéreas sensibles o vulnerables ¿Creéis que a la hora de afrontar las problemáticas urbanas deberíamos centrar más los esfuerzos en caracterizar a los habitantes que habitan nuestras ciudades e incluir sus radiografias como parte del diagnóstico urbano? ¿Consideráis necesario que este diagnóstico se realice por equipos de trabajo multidisciplinares?

AJ: Estoy de acuerdo en que es necesario entender que la crítica debe desplazarse de los argumentos a los resultados. Las ciudades son construcciones colectivas 
que rara vez se comportan como previeron sus autores. Por otro lado, las realidades urbanas son complejas, heterogéneas y cambiantes, y esas características sólo pueden ser atendidas si están representadas en superficies de inscripción que permitan su presencia en las tomas de decisiones.

Es importante señalar que en las ciudades existen realidades y sectores sociales hiperrepresentados y otros marginalizados. Que existen operadores con gran capacidad que se equipan para resultar invisibles y por tanto inescrutables. Es una responsabilidad civil la creación de descripciones de la ciudad que puedan dar simetría en la visibilidad a todas estas realidades. Y que, así, permitan exigir responsabilidad a aquéllos que toman decisiones desde la autoridad pública.

FM: Sin buenas diagnosis no hay buenas políticas. Contar, pues, con mejores diagnosis de los espacios urbanos y de quienes los habitan deviene en el momento actual una necesidad imperiosa. Si tenemos en cuenta que actualmente hablamos de sociedades urbanizadas mucho más dinámicas, cambiantes y con mayor capacidad para generar mutaciones en el uso de los espacios urbanos, convendremos en que la evaluación atenta y continua (monitoring) de los procesos urbanos es un tema de gestión de la ciudad de carácter claramente estratégico. En ese sentido, creo importante hacer dos consideraciones:

En primer lugar, los registros estadísticos con los que contamos son prácticamente los mismos y atienden a las mismas variables que hace cincuenta años. Esto es, todos ellos coinciden en considerar la ciudad como un lugar de densidad. Ocurre, sin embargo, que la ciudad hoy en día se define mucho más a partir de los patrones de movilidad que en función de cualquier otro parámetro. De esta forma, hay una gran parte de la dinámica urbana de barrios y ciudades que queda, sencillamente, oculta: ni los flujos de movilidad ni las poblaciones flotantes - ocasionales, visitantes o turistas - aparecen representados en su dimensión real. Tenemos, así pues, mucha información sobre los habitantes de la ciudad, pero muy poca sobre los usuarios del espacio urbano a los que llamo territoriantes.

En segundo lugar, la estadística moderna consideraba a los habitantes de la ciudad como un mero recurso $y$, en ese sentido, un mero input contable. Las poblaciones urbanas actuales, en cambio, tienen una asombrosa capacidad para generar nuevos outputs, esto es, nuevos procesos que los registros deberían ser capaces de seguir y no es así. Es lo que ocurre con la velocidad con la que los usos tecnológicos cambian los comportamientos en la ciudad y generan nuevos fenómenos y dinámicas urbanas, las cuales quedan expuestas a nuestra experiencia urbana cotidiana pero, en cambio, quedan ausentes del diagnóstico técnico urbano.

Con respecto a los modos de acceso al alojamiento - que no al mercado de la vivienda-, ambos afirmáis que en la cotidianeidad del habitar existe una realidad sumergida que no se refleja en datos oficiales, difícil de cuantificar (pisos compartidos, la realidad de la inmigración, ocupaciones temporales por población estudiantil, etc.). Del mismo modo, existe cierta desinformación por parte del usuario sobre otros modos de acceso al alojamiento alternativos a la propiedad. Además de actuar generando niveles de información al usuario, ¿de qué forma creéis que se puede actuar como ciudadano, profesional $y$ docente?

AJ: Como siempre es una labor lenta y colectiva. Se trata de crear un clima en el que se entienda que la legalidad y la institución son necesarias, y que paulatinamente incluyan una diversidad de situaciones que ahora quedan externas a ella. Lo mismo ocurre con la transparencia y la igualdad de oportunidades en el acceso a la vivienda. Por eso me preocupa tanto el despiste con que grupos supuestamente socio-sensibles piden acción en lugar de institución, o una desregulación de la actividad constructiva tomándose la justicia por su mano en nombre de las acupunturas urbanas o conceptos similares. Todas ellas son ideas liberales que contribuyen a consolidar hegemonías y a desplazar a la periferia a los sectores sociales más frágiles.

FM: La relación de la población con el recurso vivienda es ciertamente peculiar en España. Por un cúmulo de razones de tipo político y económico, el hecho es que la presencia de la vivienda de alquiler es poco menos que testimonial, sobre todo si se atiende a las conocidas características de debilidad y rigidez de la oferta. Al mismo tiempo, los últimos veinte años han asistido a la irrupción de procesos de globalización urbana, los cuales han impulsado tanto procesos de degradación del parque de alojamientos, como la gestación de una importante bolsa de estancias temporales para las poblaciones flotantes y turistas.

Sin duda, el mayor riesgo de la situación actual es el de acabar consolidando un mercado residencial en las ciudades claramente dualizado: en un lado, los 

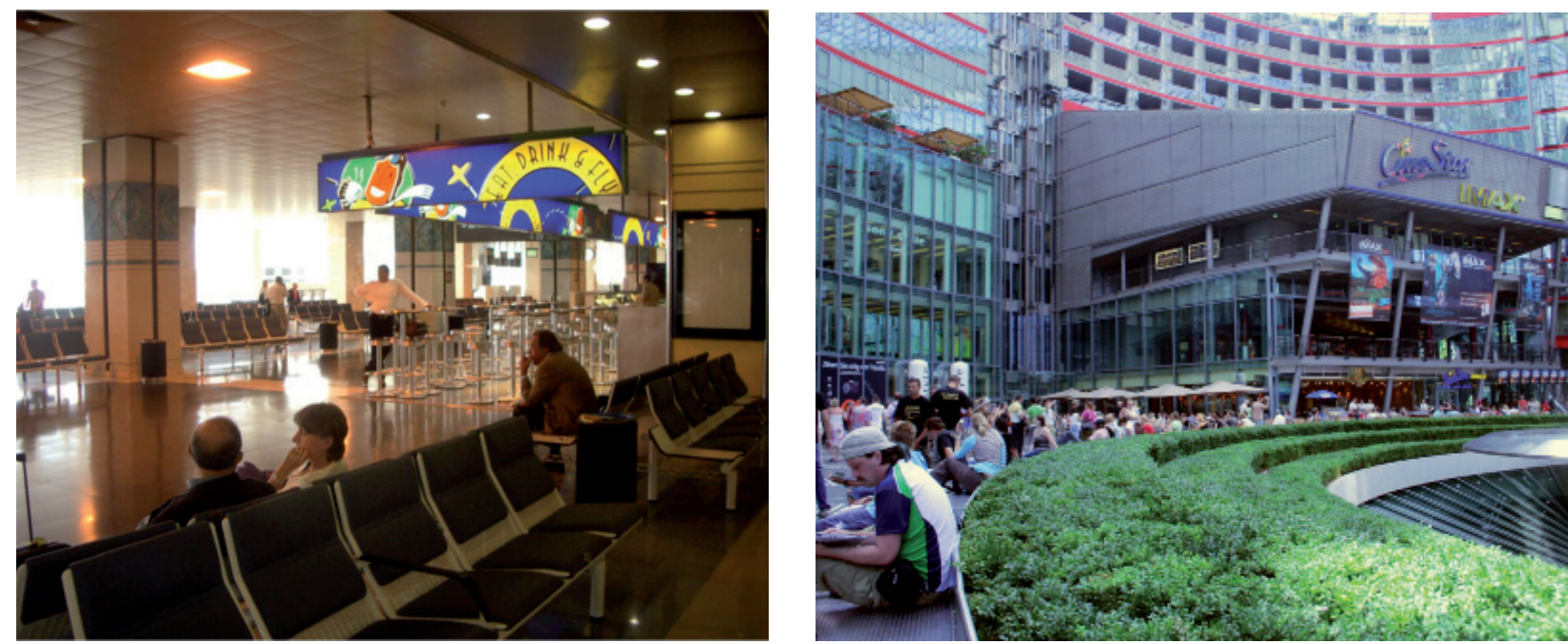

3 (Izda.) Escalas de proximidad: Eat, drink \& fly; pasajeros esperando su vuelo en un aeropuerto (2010). 4 (Dcha.) Nuevos usos del espacio público: interior del edificio Sony en la Potsdamer Platz, Berlín (2008).

compradores de vivienda, que a buen seguro habrán pasado un tiempo en el mercado de alquiler pero habrán decidido pasar al mercado de compra toda vez decidido iniciar un proyecto vital o familiar. En otro, la variadísima galería de situaciones que representa el alquiler y que incluiría de alguna manera la realidad sumergida que se menciona en la pregunta. En mi opinión, mientras el acceso a la vivienda en propiedad esté primado, los proyectos de sensibilización, información y promoción de formas alternativas de acceso al alojamiento difícilmente pasaran de tener un interés meramente testimonial.

Francesc Muñoz defiende que la ciudad surge de una multiplicación de paisajes comunes sin temporalidad ni espacialidad reales que, sin embargo, cambian sus usos originales por otros no previstos (como las gasolineras en la ciudad dispersa)'; mientras que Andrés Jaque trabaja con una ciudad que se genera en torno a la producción social de los espacios ${ }^{10}$. Al final, el modo en el que nos relacionamos determina el uso de las ciudades: quedar en un bar o en otro para tomar un café o trabajar puede depender, además de aspectos más tradicionales como el producto que ofrecen, de la música, el ambiente o su conexión wifi gratuita. En otras palabras, las prácticas urbanas constituyen una de las claves del éxito o fracaso de un espacio público. Esto, a pequeña escala es más fácil de determinar, pero cuando nos enfrentamos a escalas mayores, el esfuerzo que conlleva una amplia recogida de datos en este tipo de estudios de corte antropológico excluye mucha información relevante. ¿Qué tipo de diagnósticos urbanos creéis que podrían establecerse para tener una idea más certera de las prácticas ciudadanas?
AJ: Yo lo veo de una manera un tanto diferente. Para mí no es demasiado productivo pensar en la ciudad como un marco material y espacial, y luego en sus habitantes y en las actividades como algo que ocurre sobre el marco previo. En mi trabajo utilizo las descripciones de la teoría de la red de actantes ${ }^{11}$, porque creo que permiten entender mejor cómo cualquier situación se produce por la asociación de cosas muy diferentes (entre ellas, personas). Pero en estas asociaciones (que siempre están evolucionando) no hay una parte fija y otra cambiante: todo es más o menos inestable, pero el cambio se produce principalmente en el tipo de relación que unas cosas establecen con otras.

Hemos estudiado en detalle cómo viven setenta y dos grupos de convivencia en Madrid, y ahora empezamos a hacer el mismo estudio en Corea. La vida de una familia no depende de la naturaleza de sus miembros, sino de la manera en que usan el coche, de cómo gestionan sus usos energéticos o cómo reciben a los abuelos. Todo esto podríamos decir que es la manera en que abuelos, nietos, coches y autopistas quedan encadenados. Este es el tipo de análisis que para nosotros es más operativo.

FM: El gran fracaso del urbanismo durante todo el siglo XX ha sido el de pensar que la arquitectura y el diseño de los espacios públicos, per se, son suficientes para generar prácticas sociales urbanas, cuando en realidad es todo lo contrario: son las prácticas sociales urbanas las que acaban dando sentido al diseño del espacio público y a la arquitectura. 
La diagnosis de los comportamientos urbanos, de los procesos de apropiación, significación y resignificación de lugares por parte de la población residente y visitante, son herramientas al servicio de un urbanismo informado que sabe detectar las puntas de iceberg. Pero ¿cómo desarrollar de manera eficiente este tipo de diagnósticos? En mi opinión, este reto representa una oportunidad interesantísima para refundar los procesos de participación ciudadana. Los procesos participativos han insistido hasta ahora en vincular al ciudadano con el momento de la toma de decisiones, cuando podrían muy bien invitarle a participar en la elaboración del diagnóstico del lugar que habita y conoce de primera mano. Después de dos décadas caracterizadas por una espectacularización de los espacios urbanos que pocas veces ha atendido a los usos existentes y emergentes en la esfera de lo público colectivo, se abre ahora la posibilidad de trabajar en la escala de la proximidad (Fig. 03-04).

La gestión del espacio público (el suelo, sus usos, los recursos) sabemos que es un aspecto de la sostenibilidad social, ya que determina la capacidad de agencia de los ciudadanos y su mayor o menor confianza en las instituciones. El crecimiento urbanístico de las últimas décadas se ha identificado con el crecimiento económico principalmente del sector privado, mediante la creación de nuevo espacio urbano. ¿Consideráis necesario que este proceso se invierta a favor de la apropiación pública de estas plusvalias?

AJ: La ciudad produce riqueza, y en una sociedad democrática las administraciones tienen la obligación de asegurar que el planeamiento y la gestión de las ciudades contribuyan a distribuir de manera equitativa el acceso a los recursos. Esta es una responsabilidad cuya importancia tiende a ser minusvalorada. Lo importante es que el término recursos hoy en día ha llegado a ser muy complejo. Recursos son la información, la representación, la instalación en la esfera de la legalidad, y por supuesto también los recursos materiales, ambientales y energéticos.

FM: El gran problema del urbanismo en la ciudad actual es la incapacidad para visualizar socialmente retornos de plusvalías con un claro contenido público colectivo. Si estos retornos no se producen, la ciudadanía experimenta un doble proceso de desconfianza — hacia las políticas - y de indiferencia — hacia la política-. Impulsar formas de apropiación pública de las plusvalías que genera el desarrollo del urbanismo, de forma más imaginativa a lo que la Ley del Suelo recoge en su argumentario, es sin duda un reto de futuro.

Ocurre, sin embargo, que el contexto actual de crisis no parece llevar, paradójicamente, a ningún cambio de modelo en lo que se refiere a la distribución pública de esas plusvalías. Antes al contrario, parecería que es el ámbito público el que está soportando el mantenimiento de unas plusvalías privadas que, si bien se sitúan en umbrales más discretos que en el anterior momento de bonanza económica, continúan siendo igual de vigentes. Considerando todo ello, los retos de la ciudadanía urbana del siglo XXI no pasan, en mi opinión, solamente por exigir este urbanismo retornable, sino que han de situarse plenamente en el ámbito del empoderamiento local y la asunción de capacidades de autogestión urbana. Sin duda, el uso de las tecnologías de la información y telecomunicación abren nuevas y prometedoras vías, de manera que es posible vislumbrar la paulatina gestación de lo que yo llamaría ciudadanía viral inteligente: una ciudadanía capaz de negociar sobre nuevas bases y con cualquier interlocutor a favor de unos retornos del proceso urbanizador más claros (Fig. 05).

$$
\star \star \star
$$

Es grato comprobar que el rigor técnico propio de los planes urbanísticos abre cada vez más espacios al pensamiento complejo. A pesar del carácter limitado de esta entrevista, las visiones convergentes de profesionales como Andrés Jaque o Francesc Muñoz facilitan una visión del mundo más acorde al de la ciudad actual.

El hombre no es un arquetipo, como apuntaba la Ilustración o la antropología clásica. Si tenemos una concepción estrictamente mensurable de la arquitectura, ésta será una concepción limitada. Si deseamos descubrir cómo vive el hombre, sólo lo podremos saber a través de sus hábitos, tal y como se apunta en diferentes momentos de esta entrevista. Se trata de comprender que los espacios de nuestras ciudades no son neutrales, sino el resultado de un momento y una realidad. No cabe duda de que la brecha que aquí se abre excede el ámbito de este texto. 


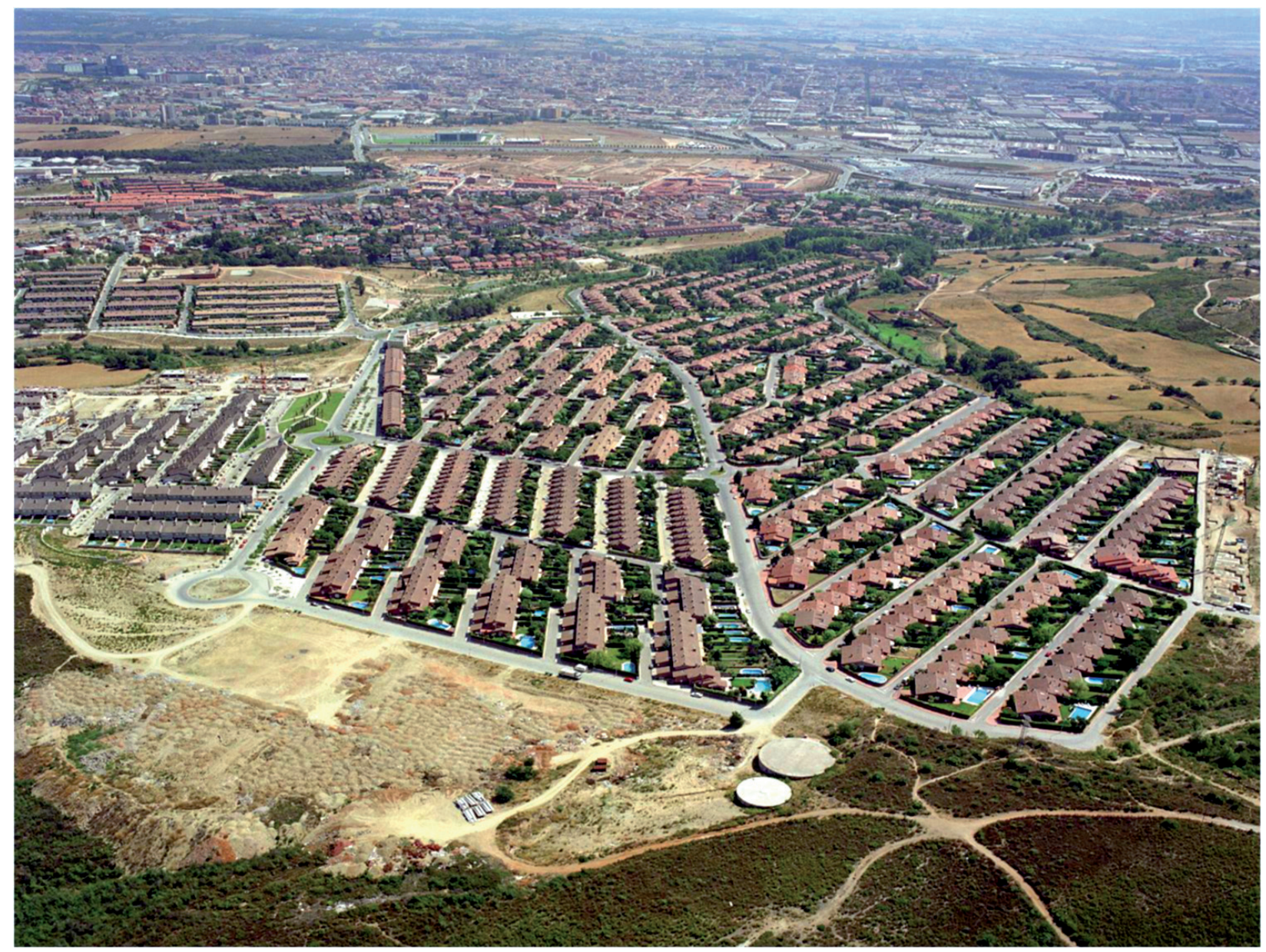

5 Nuevos barrios de vivienda unifamiliar de baja densidad: Sant Quirze del Vallès, Barcelona (2010).

Notas

1. Historias de cronopios y de famas (1962) es el título de la obra surrealista del escritor argentino Julio Cortázar. Se ha adoptado dicho título por presentarse aquí un diálogo a tres bandas partiendo de fragmentos, como sucede en la obra de referencia. Con la elección del título se permite al lector interpretar los tres escenarios aquí planteados, partiendo de las tres visiones del universo presentadas en la obra de Cortázar.

El Foro para la Edificación Sostenible de la Comunitat Valenciana (Foro ESCV) es un espacio de debate entre la administración, los agentes intervinientes en el sector de la edificación y la ciudadanía. Entre sus acciones destacan las Ediciones Abiertas que periódicamente reúnen a la red de profesionales pertenecientes al Foro ESCV y a profesionales de prestigio.

Andrés Jaque Ovejero dirige la firma Andrés Jaque Arquitectos y el tiny lab Oficina de Innovación Política, ambas comprometidas con la exploración del papel de la arquitectura en la construcción de las sociedades, y administra desde 2004 la marca de calidad Arquitectura Parlamento. Es profesor en la Universidad Europea de Madrid y es habitualmente invitado a numerosos centros universitarios de prestigio internacional. Por su parte, Francesc Muñoz Ramírez dirige el Observatori de la Urbanització y del Màster en Intervenció i Gestió del Paisatge de la Universitat Autònoma de Barcelona.

2. Max Weber, El politico y el científico (Madrid: Alianza, 1998). Se trata de una transcripción de la conferencia impartida por Max Webber en 1918 por invitación de la Asociación Libre de Estudiantes de Munich. Según Webber, es imposible ser al mismo tiempo hombre de acción y hombre de ciencia sin entrar en profundas contradicciones entre ambas vocaciones.

3. Este planteamiento no es novedoso. En numerosas ocasiones, el rol del arquitecto ha excedido el ámbito de la técnica, como por ejemplo en el caso de Jane Jacobs y los arquitectos de los años sesenta (cf. Jane Jacobs, The Death and Life of Great American Cities (New York: Vintage Books, 1961). En la actualidad, en muchas ocasiones se mantiene la idea de que el desarrollo científico y técnico es en sí mismo la base de legitimación de las fuerzas productivas, tal y como planteaba Jürgen Habermas en Ciencia y técnica como "ideología" (Madrid: Tecnos, 1986: 57).

4. La Teoría Actor-Red (o ANT en inglés) es un enfoque sociológico originado en el campo de los estudios sociales de la ciencia de la mano de Bruno Latour a finales de los ańos ochenta. Dicho enfoque se ha aplicado al ámbito de la docencia universitaria a través del proyecto Análisis de controversias, como parte del proyecto de investigación MACOSPOL (Mapping controversies in science and technology for politics), financiado por la Comisión Europea en la convocatoria VII Programa Marco de Investigación y Desarrollo. Para entender el germen de la ANT conviene consultar: Bruno Latour, La ciencia en acción. Cómo seguir a los científicos e ingenieros a través de la sociedad (Barcelona: Labor, 1992).

5. El concepto de técnico se entiende como aquél que apoya los hechos científicos construyendo la sociedad a partir de la naturaleza (como las diversas ramas del realismo) (Idem., 252). 
Como he indicado anteriormente, varias iniciativas internacionales han puesto en práctica dicho enfoque. A nivel nacional, una de ellas se refleja en el artículo de Fabián Muniesa Manuel e Izaskun Chinchilla Moreno "La controversia como herramienta proyectual”, Boletín CF+S 32/33 (2004): sp.(http://habitat.aq.upm.es/boletin/n32/aichi01.html). Por otro lado, procede hacer referencia al artículo de Andrés Jaque "Defensa de la intolerancia en las escuelas de arquitectura. Cyber-santuarios, telenovelas y villas saboyas en la formación del arquitecto post-humanista”, Arquitectos 180 (2007): 63-67, en el que se incide en las limitaciones pedagógicas de las escuelas de arquitectura españolas.

6. Cf. "Casa rodante para una sociedad rodante", El Croquis 148-II (2010): 2-24 y 244 ss.

7. Véanse por ejemplo los planteamientos de Zaida Muxí en "Ciudad Próxima: Urbanismo sin género", Ingeniería y Territorio: la ciudad habitable 75 (2006): 68-78; Francesco Tonucci, "La ciudad de los nińos", Ingeniería y Territorio: la ciudad habitable 75 (2006): 60-68; para una visión general sobre las teorías del desarrollo humano puede verse Alfonso Dubois "Definición y elementos centrales del concepto de Desarrollo Humano", en Alejandra Boni et al. (coord.), Construir la ciudadanía global desde la Universidad (Barcelona: Intermón Oxfam/Ingeniería sin Fronteras, 2006), 53-66.

En el campo de la arquitectura, el concepto de desarrollo a escala humana introducido por Manfred A. Max-Neef, Antonio Elizalde y Martín Hopenhayn se está enclavando como estrategia de revitalización de barrios. Véase, por ejemplo, la propuesta presentada en el Congreso SB10MAD-GBCe (2010) por Agustín Hernández Aja et al. "Revitalización de barrios y teoría de las necesidades: un enfoque participativo" (www.sb10mad.com/ponencias/archivos/c/C046.pdf; con acceso, junio de 2011).

8. Por ejemplo, en Francia existe el Observatoire National des Zones Urbaines Sensibles, en Bélgica el Analyse Cartographique des Quartiers en Difficulté, etc. 9. Francesc Muñoz Rodríguez, Urbanalización. Paisajes comunes, lugares globales (Barcelona: Gustavo Gili, 2008).

10. Andrés Jaque Ovejero, Excepto 25. Andrés Jaque. Políticas del día a día (Madrid: Fundación Cultural COAM, 2011).

11. Terminología específica de la Teoría del Actor-Red (ANT) de la cual Andrés Jaque se hace eco en numerosas ocasiones. Los actantes tienen la particularidad de ser actores tanto humanos como no humanos, e intervienen de modo activo a la hora de definir una situación. Se puede observar un caso práctico en el estudio de Bruno Latour y Steve Woolgar La vida en el laboratorio. La construcción de los hechos científicos (Madrid: Alianza, 1995).

\section{Procedencia de las ilustraciones}

Fig. 1 y 3: Francesc Muñoz Ramírez.

Fig. 2: Miguel de Guzmán (www.imagensubliminal.com).

Fig. 4: Ángela Peinado García.

Fig. 5: Jordi Todo Vila.

\section{Sobre la autora}

Carolina Mateo trabaja en el Instituto Valenciano de la Edificación, desarrollando I+D sobre evaluación de políticas públicas en relación al acceso a la vivienda y la ciudad y la monitorización de la sostenibilidad a escala urbana. En relación a estos temas, participa activamente en programas internacionales como Climate Kic (EIT-UE) y los trabajos desarrollados por Sustainable Building Alliance. También colabora en la coordinación del Foro para la Edificación Sostenible de la Comunitat Valenciana. En el ámbito académico, es profesora de Grado de Arquitectura de la Universidad Europea de Madrid/ Centro Adscrito Valencia, donde imparte las asignaturas de Áreas Urbanas y Diseño Sostenible y Taller Proyectual a Escala Antropométrica. Arquitecta (2004) con las especialidades de Edificación (UPV) y Urbanismo (La Sapienza-Roma). Máster en Políticas y Procesos de Desarrollo (UPV, PUC Minas-Brasil, 2009) y Diploma de Estudios Avanzados (Departamento de Proyectos Arquitectónicos-UPV, 2010).

carolina.mateo@uem.es / carolinamateocecilia@gmail.com 